\title{
ANALISA SISTEM INFORMASI REPOSITORY PADA UPT PERPUSTAKAAN UNIVERSITAS BENGKULU DENGAN COBIT 5
}

\author{
${ }^{1}$ Arie Vatresia, ${ }^{2}$ Ferzha Putra Utama, Tiara E Febrianti ${ }^{1}$ \\ ${ }^{1}$ Informatika, Universitas Bengkulu, Indonesia \\ ${ }^{2}$ Sistem Informasi, Universitas Bengkulu, Indonesia \\ larie.vatresia@unib.ac.id; ${ }^{2}$ fputama@unib.ac.id; ${ }^{3}$ rara45145@gmail.ac.id;
}

\section{Article Info}

Article history:

Received, 04-12-2021

Revised, 28-12-2021

Accepted, 15-01-2021

\section{Kata Kunci:}

COBIT 5

Sistem Perpustakaan

Universitas Bengkulu

Analisis gap

Delivery and Support

\begin{abstract}
ABSTRAK
Teknologi informasi selalu berperan pada kemajuan dalam berbagai bidang usaha [1]-[3]. Namun dalam praktiknya setiap bidang usaha dengan teknologi informasi selalu berpeluang mengalami kerugian dan ancaman lainnya, sehingga diperlukan evaluasi ataupun audit untuk menghindari risikonya [2], [4][5]. Selain pada bidang usaha, lingkungan kampus yang menerapkan teknologi informasi juga dapat dilakukan evaluasi dan audit, terlebih lagi sistem universitas dengan konsep Badan Layanan Umum (BLU). Salah Unit Pengelola Teknis (UPT) Perpustakaan Universitas Bengkulu memilki sistem repositori yang digunakan sebagai layanan publik. Penelitian ini bertujuan untuk mengetahui sejauh mana kinerja sistem informasi repositori yang ada di UPT Perpustakaan Universitas Bengkulu sebagai layanan publik yang telah diterapkan pada Universitas Bengkulu. Dari penelitian ini diharapkan dapat memberikan rekomendasi untuk tata kelola inovasi kepada UPT perpustakaan UNIB setelah mengetahui kesenjangan antara tatakelola saat ini dengan tatakelola yang diharapkan pada tujuan organisasi. Kerangka kerja (framework) yang digunakan dalam melakukan audit pada penelitian ini adalah COBIT versi 5 khusus pada domain Deliver and Support (DS) [6]-[9]. Teknik pengumpulan data yang dilakukan yaitu dengan studi literatur, observasi, wawancara dan kuisioner [2], [6], [10]. Hasil dari penelitian ini adalah tingkat kematangan (maturity level) pada implementasi sistem informasi repository khusus pada Domain DS, yaitu berada pada level 4 yang berarti sudah terukur dan terintegrasi antar proses yang berlangsung [11], [12]. Dan analisa GAP antara kondisi yang diharapkan dengan kondisi saat ini rata-rata sebesar 0,6.
\end{abstract}

\section{ABSTRACT}

Information technology has always played a role in advances in various business fields [1]-[3]. However, in practice every business sector with information technology always has the opportunity to experience losses and other threats, so that evaluation or audit is required to avoid the risk [2], [4][5]. In addition to the business sector, campus environments that apply information technology can also be evaluated and audited, especially the university system with the concept of a Public Service Agency (BLU). One of the Technical Management Units (UPT) of the Bengkulu University Library has a repository system that is used as a public service. This study aims to determine the performance of the repository information system in the UPT Library of Bengkulu University as a public service that has been implemented at the University of Bengkulu. From this research, it is hoped that it can provide recommendations for innovation governance to the UPT of UNIB libraries after knowing the gap between current governance and expected governance of organizational goals. The framework used in conducting audits in this study is COBIT version 5 specifically in the Deliver and Support (DS) domain [6]-[9]. The data collection technique used was literature study, observation, interview and questionnaire [2], [6], [10]. The results of this study are the maturity level in the implementation of a special repository information system in the DS Domain, which is at level 4, which means that it is measured and integrated between ongoing processes [11], [12]. And the GAP analysis between the expected conditions with the current conditions is an average of 0.6 . 


\section{Penulis Korespondensi:}

Ferzha Putra Utama

Program Studi Sistem Informasi,

Universitas Bengkulu,

Email: fputama@unib.ac.id

\section{Pendahuluan}

Tren maksimalisasi Teknologi Informasi (TI) dalam investasi bisnis organisasi telah muncul belakangan ini karena meningkatnya tuntutan kualitas layanan dan minimisasi biaya dari masyarakat, pasar, dan dalam organisasi itu sendiri [2], [13], [14]. Pengenalan aplikasi TI dalam suatu organisasi diketahui dapat meningkatkan nilai bisnis organisasi dalam kegiatan utama dan anak perusahaan. Selain itu, TI digunakan sebagai sarana strategis untuk meningkatkan keunggulan kompetitif organisasi selama masa ketidakpastian [2], [15]. Hal ini berkontribusi pada peningkatan ketergantungan lingkungan kerja yang ramah TI, di mana manajemen TI yang efektif yang kompatibel dengan tujuan bisnis sangat penting untuk memastikan keberhasilan organisasi.

Perpustakaan merupakan salah satu organisasi non-profit yang bergerak di bidang jasa yang juga tidak terlepas dari perkembangan teknologi informasi [10], [16], [17]. Oleh karena itu, perpustakaan harus mampu memanfaatkan keberadaan teknologi informasi dan untuk itulah dibutuhkan suatu perencanaan evaluasi dan strategis di bidang teknologi informasi. Ada beberapa faktor yang mendukung perlunya perencanaan evaluasi dan strategis dalam sistem informasi di perpustakaan. Pertama, terdapat pola pemanfaatan internet yang terus meningkat. Kedua, sebagai sarana dan upaya dalam meningkatkan efisiensi. Ketiga, agar perpustakaan memiliki sebuah panduan untuk menentukan teknologi dan proyek teknologi informasi yang akan diterapkan dalam satu sampai dengan lima tahun ke depan serta anggaran yang diperlukan setiap tahunnya.

Faktor utama yang mendorong Perpustakaan Universitas Bengkulu perlu memiliki evaluasi dan strategis di bidang teknologi informasi ialah poin ketiga dalam Misi UPT Perpustakaan Universitas Bengkulu yang berbunyi "Mengembangkan koleksi bahan pustaka dalam bentuk digital dan virtual", maka dari poin tersebut pengembangan sistem informasi sebagai pendukung pustaka digital sangatlah dibutuhkan sehingga dapat mewujudkan visi misi Perpustakaan Universitas Bengkulu. Berdasarkan latar belakang tersebut maka evaluasi dan strategis teknologi pada sistem informasi repsitory diperlukan untuk Perpustakaan Universitas Bengkulu sehingga memiliki panduan berupa strategi-strategi yang harus dijalankan di bidang sistem informasi dan agar memiliki kinerja yang lebih baik, juga memberikan keuntungan kompetitif sehingga dapat bersaing di era global.

Evaluasi kinerja Sistem Informasi dan Teknologi Informasi pada UPT Perpustakaan Univesitas Bengkulu berdasarkan keputusan yang diambil oleh peneliti melalui observasi dan studi literatur dapat dilakukan dengan menggunakan framework COBIT (Control Objective for Information and related Technology). Dikembangkan oleh Information System Audit and Control Association (ISACA) dan IT Governance Institute (ITGI), COBIT adalah salah satu kerangka kerja manajemen Teknologi Informasi. COBIT 5 framework memuat tujuan pengendalian yang terdiri dari 5 domain, yaitu Align, Plan and Organise (APO), Build, Acquire and Implement (BAI), Deliver, Service and Support (DSS) serta Monitoring, Evaluate and Assess (MEA), Evaluate, Direct and Monitor (EDM). Dengan diperkenalkan COBIT 5, dan kini tujuan analisis menjadi: efektivitas, efisiensi, kerahasiaan, keterpaduan, ketersediaan, kepatuhan pada kebijakan/aturan dan keandalan sistem informasi [12], [18]-[20].

Penelitian ini menggunakan Domain DS (Deliver and Support) yang berfokus pada penilaian manajemen operasi, pengiriman dan layanan teknologi informasi serta dukungannya terhadap proses bisnis yang berlangsung termasuk juga pengelolaan masalah agar keberlanjutan proses bisnis tetap terjaga serta bagaimana mengontrol proses bisnis, mengevaluasi, dan merencanakan secara jangka panjang proses bisnis ke depan [4], [12], [21]. Evaluasi tingkat kematangan harus diukur secara periodik dan tidak hanya satu 
domain [6], [22], [23], namun perlu juga melibatkan domain lainnya agar memiliki kesatuan informasi yang jelas dan terukur dalam perumusan dan perencanaan tata kelola teknologi informasinya dalam mencapai tingkat kematangan yang diharapkan.

\section{Metode Penelitian}

\subsection{Metode Pengumpulan Data}

1) Studi Literatur

Studi literatur dilakukan oleh penulis dengan mempelajari buku-buku, jurnal, paper, dan bacaan yang terdapat kaitannya dengan judul penelitian baik berupa softcopy maupun hardcopy.

2) Observasi

Observasi dilakukan oleh penulis dengan langsung terjun ke lapangan saat kerja praktik dengan mengamati serta mempraktikkan bagaimana proses berjalannya sistem infomasi repositori yang ada di UPT Perpustakaan Universitas Bengkulu. Penulis ikut serta dalam pengisian data di sistem informasi repositori di UPT Perpustakaan Universitas Bengkulu di bawah didikan pembimbing lapangan selama berlangsungnya kerja praktik.

3) Wawancara

Kegiatan wawancara dilakukan juga oleh penulis sebagai bentuk upaya dalam pengumpulan data. Wawancara diajukan oleh penulis terhadap pembimbing lapangan. Untuk proses wawancara dilakukan secara bertahap atau tidak dalam satu hari penuh. Proses wawancara dilakukan oleh penulis setiap kali selesai melakukan kerja praktik atau ketika ditemui adanya kejanggalan pada sistem repositori yang dijalankan oleh penulis.

4) Kuisioner

Setelah dilakukan kegiatan observasi dan wawancara, penulis juga membuat kuisioner menggunakan media online google form yang disebarkan pada pihak perpustakaan dan pihak mahasiswa atau alumni selaku pihak yang menggunakan sistem informasi repositori pada UPT Perpustakaan Universitas Bengkulu. Isi dari kuisioner yang dibuat oleh penulis ialah beberapa pertanyaan yang terkait dengan kinerja sistem informasi repositori pada UPT Perpustakaan Universitas Bengkulu. Dan kuisioner yang dibuat oleh penulis ialah bersifat tertutup atau penulis telah menyediakan pilihan jawaban untuk dipilih oleh responden yang ditujukan.

\subsection{Metode Analisis}

Pada analisis sistem informasi repositori UPT Perpustakaan Universitas Bengkulu, penulis menggunakan Framework COBIT 5[8], [13], [17], [24]yang telah menyediakan domain-domain mendukung untuk analisis sistem informasi.

\section{Hasil dan Pembahasan}

\subsection{Framework COBIT 5}

Menurut [4], [18], [19] Cobit 5 merupakan satu kerangka kerja bisnis untuk tata kelola dan manajemen perusahaan TI. Versi evolusioner ini menggabungkan pemikiran terbaru dalam tata kelola perusahaan dan teknik manajemen, serta menyediakan prinsip-prinsip, praktik, alat-alat analisis dan model yang diterima secara global untuk membantu meningkatkan kepercayaan, dan nilai dari sistem informasi. COBIT disusun oleh the IT Governance Institute (ITGI) dan Information Systems Audit and Control Association (ISACA). COBIT Framework mencakup tujuan pengendalian yang terdiri dari 4 domain yaitu:

1) Perencanaan dan Organisasi (Plan and Organize) yaitu mencakup pembahasan tentang identifikasi dan strategi investasi TI yang dapat memberikan yang terbaik untuk mendukung pencapaian tujuan bisnis.

2) Perolehan dan Implementasi (Acquisition and Implementation) yaitu untuk merealisasi strategi TI, perlu diatur kebutuhan TI, diidentifikasi, dikembangkan, atau diimplementasikan secara terpadu dalam proses bisnis perusahaan. 
3) Penyerahan dan Pendukung (Delivery and Support), domain ini lebih dipusatkan pada ukuran tentang aspek dukungan TI terhadap kegiatan operasional bisnis (tingkat jasa layanan TI aktual atau service level) dan aspek urutan (prioritas implementasi dan untuk pilihannya).

4) Monitoring yaitu semua proses TI yang perlu dinilai secara berkala agar kualitas dan tujuan dukungan TI tercapai, dan kelengkapannya berdasarkan pada syarat kontrol internal yang baik.

\subsection{Tingkat Kematangan (Maturity Level)}

Salah satu objek pengukuran pada kinerja suatu sistem teknologi informasi ialah dengan melakukan pengukuran pada tingkat kematangan (maturity level) [6], [14]. Tingkat kematangan untuk pengelolaan dan pengendalian pada proses teknologi informasi didasarkan pada metode evaluasi organisasi sehingga dapat mengevaluasi sendiri dari level 0 (tidak ada) hingga level 5 (Optimis). Pendefinisian tingkat kematangan suatu proses teknologi informasi, COBIT mempunyai tingkat kematangan untuk mengontrol proses-proses TI dengan menggunakan metode penilaian (scoring).

Menurut [4], [6], [25], tingkat kematangan merupakan gambaran kematangan prosesteknologi informasi yang berlangsung pada sebuah perusahaan. Model kematangan dapat digunakan sebagai alat untuk melakukan benchmarking dan self-assessment oleh manajemen teknologi informasi untuk menilai kematangan teknologi informasi yang telah diimplementasikan. Dengan model kematangan, manajemen dapat mengidentifikasikan hal-hal sebagai berikut:

1) Kinerja actual dari perusahaan - posisi perusahaan saat ini.

2) Status industry saat ini-perbandingan.

3) Target perbaikan bagi perusahaan-kemana perusahaan akan dibawa.

4) Arah pengembangan yang diperlukan dari as-is menjadito-be.

\subsection{Indikator Prosses Kapabilitas}

Pada COBIT versi 5 [24][25] juga ada maturity model, yaitu berfungsi menentukan skala kematangan COBIT, ada 6 tingkatan yang terdiri dari:

1. Level 0: Non-Existent yang melakukan Pengelolaan teknologi informasi/sistem informasi masih dalam tahap paling awal, masih pemula. Setiap proses belum terdefinisi dengan baik.

2) Level 1: Initial/Ad Hocc Organisasi telah menyadari adanya persoalan yang perlu ditangani, tetapi belum adanya standar proses yang harus dilakukan.

3) Level 2: Repeatable but Intuitive Proses telah dikembangkan pada tahap ini sehingga telah dilakukan prosedur yang sejenis untuk kegiatan yang sama.

4) Level 3: Defined Process, Prosedur telah distandarisasi, didokumentasikan, dan dikomunikasikan melalui pelatihan. Tahap ini mulai mengenal metodologi pengembangan sistem dan masih sangat tergantung individu apakah mengikuti standar yang ada maupun tidak, tetapi telah ada formalisasi untuk setiap kegiatan.

5) Level 4: Managed and Measurable, Pada tahap ini manajemen mengawasi dan mengukur halhal yang telah dipenuhi dengan prosedur, serta mengambil tindakan ketika proses tidak berjalan dengan efektif.

6) Level 5: Optimised, Proses yang ada telah disesuaikan dengan best practice, berdasarkan hasil pengembangan secara terus-menerus dengan organisasi-organisasi lain. Teknologi informasi digunakan sebagai bagian yang terintegrasi dengan aliran kerja, sebagai alat bantu untuk meningkatkan kualitas dan efektivitas, dan membuat organisasi dapat dengan cepat untuk beradaptasi.

\subsection{Ruang Lingkup Deliver,Service and Support (DSS)}

Delivery, Service and Support terdapat enam proses [11][12][13], yaitu domain proses yang berhubungan dengan pelayanan yang diberikan, seperti operasi tradisional terhadap keamanan dan aspek kesinambungan hingga pelatihan yang meliputi :

1) DSS01-Manage operations (Mengelola mengkoordinasikan dan melaksanakan kegiatan dan prosedur operasional) 
2) DSS02-Manage service request and incidents (Memberikan respon yang tepat waktu dan efektif untuk permintaan pengguna dan resolusi senua jenis kejadian)

3) DSS03-Manage problems (Mengidentifikasi dan mengklasifikasikan masalah dan memberikan solusi perbaikan yang tepat)

4) DSS04-Manage continuity (Mengelola layanan yang berkelanjutan yang memungkinkan bisnis dan TI mennaggapi kejadian dan gangguan proses operasi bisnis)

5) DSS05-Manage security service (Mengelola layanan keamanan untuk melindungi informasi organisasi dan mempertahankan tingkat resiko keamanan informasi)

6) DSS06-Manage business process controls (Mengelola proses bisnis yang tepoat untuk memastikan bahwa informasi memenuhi persyaratan pengendalian informasi yang relevan)

\subsection{Analisis dan Pemetaan RACI Chart}

RACI Chart [17], [26] adalah diagram yang disediakan oleh Framework COBIT 5 sebagai acuan dalam menentukan antara responden dan domain berdasarkan proses yang dipilih dalam penelitian yang diangkat dari standarisasi ISACA. RACI merupakan susunan jabatan yang bisa dijadikan pedoman dalam memilih partisipan penelitian. Responden yang dipilih adalah responden yang mewakili tabel RACI (Responsibility, Accountability, Consult, and Inform) pada proses pengolahan data berikut ini adalah RACI chart untuk masing-masing domain [17], [27]. RACI Chart terdiri empat parameter, yaitu:

1) Responsible, yaitu orang yang melakukan tugas atau pekerjaan. Responsible pada dasarnya adalah pelaksana tugas.

2) Accountable, yaitu orang yang bertanggung jawab pada suatu tugas atau pekerjaan dan memiliki wewenang untuk memutuskan suatu permasalahan atau perkara. Accountable yang dimaksud di sini pada dasarnya adalah penanggung jawab dan pengambil keputusan.

3) Consulted, yaitu orang yang memberikan masukan, pendapat atau kontribusi ketika diperlukan pada tugas atau pekerjaan tersebut. Consulted pada dasarnya adalah konsultan ataupun penasehat.

4) Informed, yaitu orang yang perlu mengetahui tindakan dan hasil ataupun keputusan yang telah diambil.

Tabel 3.1 Diagram RACI dalam bentuk tabel

\begin{tabular}{|c|c|c|c|c|c|}
\hline \multirow[t]{2}{*}{ Deskripsi } & \multicolumn{5}{|c|}{ Responden } \\
\hline & 1 & 2 & 3 & 4 & 5 \\
\hline DSS01- Manage Operations & $\mathbf{C , I}$ & $\mathbf{C , I}$ & $\mathbf{R}, \mathbf{I}$ & $\mathbf{R}, \mathbf{A}$ & $\mathbf{R}, \mathbf{I}$ \\
\hline DSS02- Manage Service Request and Incident & - & - & - & - & - \\
\hline DSS03-Manage Problems & - & - & - & - & - \\
\hline DSS04-Manage Continuity & $\overline{\mathbf{A}, \mathbf{C}, \mathbf{I}}$ & $\mathbf{I}$ & $\mathbf{R}, \mathbf{C}, \mathbf{I}$ & $\mathbf{R , C , I}$ & $\mathbf{R , C , I}$ \\
\hline DSS05-Manage Security Sevice & $\mathbf{I}$ & $\mathbf{I}$ & $\mathbf{R}, \mathbf{C}, \mathbf{I}$ & $\mathbf{R}, \mathbf{A}$ & $\mathbf{R}, \mathbf{C}, \mathbf{I}$ \\
\hline DSS06-Manage Business Process Controls & - & - & - & - & \\
\hline
\end{tabular}

Keterangan:

Responden 1: Pegawai dari bidang Pengelolaan yang sering terlibat pada bidang TI

Responden 2: Pegawai dari bidang Layanan Sirkulasi yang sering terlibat pada bidang TI

Responden 3: Kepala Bidang IT

Responden 4: Karyawan bidang IT

Responden 5: Karyawan bidang IT

Berdasarkan tabel 3.1 maka dapat diperoleh terdapat 5 responden yang akan masuk ke dalam proses penelitian terkait dengan bidang IT pada analisis. Dan dari tabel 4.1 dapat diketahui dari 6 proses yang terdapat pada domain DSS (Deliver, service and Support) [29][30] hanya terdapat 3 proses yang dapat digunakan dalam penelitian berdasarkan pengelompokkan kinerja responden. Kemudian hasil dari pemetaan RACI akan dibuat dalam bentuk kuesioner untuk responden sesuai dengan hasil dari pemetaan RACI tersebut. 


\subsection{Hasil Analisis Penilaian Tingkat Kematangan Tiap Domain}

Berdasarkan kuesioner tingkat kematangan pada Sistem Informasi Repositori UPT Perpustakaan menggunakan COBIT 5 dengan narasumber 3 orang dari devisi Teknologi Informasi, 1 orang dari devisi pengelolaan serta 1 orang dari devisi Layanan Sirkulasi, dengan penilaian kuesioner berdasarkan indikator sebagai berikut:
- Optimal = 5
- Terkelola $=4$
- Ditetapkan $=3$
- Dapat Diulang $\quad=2$
- Inisialisasi $=1$
- Tidak Ada $\quad=0$

Setelah dilakukannya penyebaran kuesioner, maka dibuatlah pemetaan terhadap posisi tiaptiap proses sistem informasi perusahaan terhadap model maturity dengan menggunakan tabeltabel. Rumus yang digunakan untuk menghitung indeks adalah:

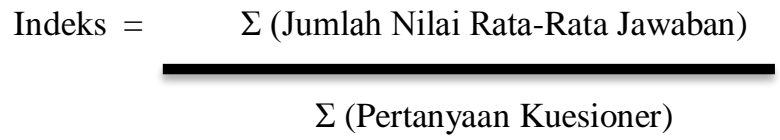

Maka hasil penilaiannnya tingkat kematangan rata-rata dari semua domainnya sebagai berikut:

Tabel 3.2 Hasil Indeks Model Maturity

\begin{tabular}{|c|c|c|c|c|c|}
\hline No & Proses & $\begin{array}{c}\text { Jumlah } \\
\text { Pertanyaan }\end{array}$ & $\begin{array}{c}\text { Jumlah } \\
\text { Nilai } \\
\text { Jawaban }\end{array}$ & Indeks & $\begin{array}{c}\text { Tingkat } \\
\text { Model } \\
\text { Maturity }\end{array}$ \\
\hline 1 & Manage Operations (DSS01) & 8 & 19.7 & 3.9 & 4 \\
\hline 2 & Manage Continuity (DSS04) & 7 & 15.6 & 3.1 & 3 \\
\hline 3 & Manage Security Service (DSS05) & 13 & 14.5 & 2.9 & 3 \\
\hline \multicolumn{4}{|c|}{ Rata-Rata } & 3.1 & 3 \\
\hline
\end{tabular}

Berdasarkan pehitungan tingkat kemaatangan sistem informasi repositori pada tabel 3.2 dapat diketahui bahwa semua proses Deliver and Support (DS) Domain Sistem Informasi repsitori, maka diperoleh rata-rata indeks 3.1 yang dapat dibulatkan menjadi 3 yang artinya sistem informasi di domain DS ini ada pada tingkat 3 yaitu Defined Process dengan makna Prosedur telah distandarisasi, didokumentasikan, dan dikomunikasikan melalui pelatihan. Tahap ini mulai mengenal metodologi pengembangan sistem dan masih sangat tergantung individu apakah mengikuti standar yang ada maupun tidak, tetapi sistem informasi ini telah cukup membantu dalan proses repositori di Universitas Bengkulu. Hal tersebut berarti bahwa proses-proses yang terdapat pada domain DS telah berjalan namun masih bisa dikatakan belum terlalu baik, karena sistem informasi repositori sendiri masih memiliki banyak kekurangan diberbagai fitur dan eror di beberapa proses berjalannya sistem.

\subsection{Analisis Keseluruhan Gap}

Berikut ini adalah hasil dari pelaksanaan audit, diperolehnya hasil capability Level untuk keseluruhan proses adalah sebagai berikut:

Tabel 3.3 Analisis Keseluruhan Gap

\begin{tabular}{|c|c|c|c|}
\hline Nama Proses & Level Existing & Level Target & GAP \\
\hline Manage Operations (DSS01) & 3.9 & 5.0 & 1.1 \\
\hline
\end{tabular}


JSAI : Journal Scientific and Applied Informatics

Vol. 4, No. 01, Januari 2021, hal. 20 28

E-ISSN: 2614-3054; P-ISSN: 2614-3062, accredited by Kemenristekdikti, Sinta 5

DOI: 10.36085

\begin{tabular}{|l|c|c|c|}
\hline Manager Continuity (DSS04) & 3.1 & 5.0 & 1.9 \\
\hline Manage Security Service (DSS05) & 2.9 & 5.0 & 2.1 \\
\hline
\end{tabular}

Dari Tabel 3.3 dan gambar 3.1 diperoleh capability Level tiap-tiap proses domain DSS COBIT 5 berada pada level 3.0 yaitu Defined Process dengan makna Prosedur telah distandarisasi, didokumentasikan, dan dikomunikasikan melalui pelatihan. Tahap ini mulai mengenal metodologi pengembangan sistem dan masih sangat tergantung individu apakah mengikuti standar yang ada maupun tidak, tetapi sistem informasi ini telah cukup membantu dalan proses repositori di Universitas Bengkulu. Hal tersebut berarti bahwa proses-proses yang terdapat pada domain DSS telah berjalan namun masih bisa dikatakan belum terlalu baik, karena khususnya pada sistem informasi repositori sendiri masih memiliki banyak kekurangan diberbagai fitur dan error di beberapa proses berjalannya sistem. Akan tetapi pada Level Existing artinya belum mencapai level yang optimum, terutama pada DSS04 Manage Contiunity dan DSS05 Manage Security Service yang berada pada tingkat kematangan dengan indeks 3, yang berarti masih sangat kurang, dan masih sangat dibutuhkan peningkatan dalam sistem informasi repositori.

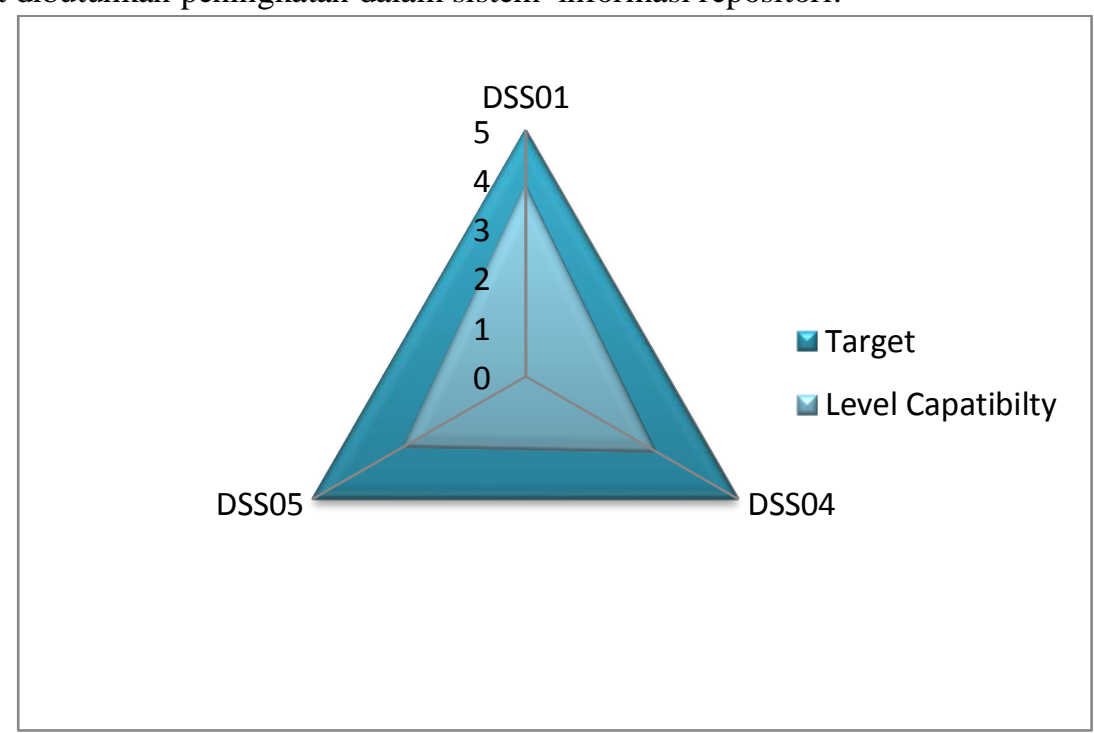

Gambar 3.1 Grafik Rata-rata Capatibility

\subsection{Rekomendasi Umum Keseluruhan Proses}

Berikut ini beberapa rekomendasi secara umum berdasar kondisi Bagian Sistem Informasi Repositori pada UPT Universitas Bengkulu. Capability Level yang diperoleh secara keseluhan adalah Level 3 yaitu Defined Process. Level target yang ingin dicapai adalah 5 optimal, sehingga rekomendasi yang disusun adalah sebagai berikut:

1) Diperlukan evaluasi secara menyeluruh dari pihak Universitas langsung mengenai tingkat kematangan kinerja yang ada pada UPT Perpustakaan Universitas Bengkulu, terutama pada sistem informasi repository.

2) Berdasarkan prioritas, maka Domain yang masih tertinggal adalah pada DSS04 Manaage Continuity dan DSS05 Manage Security Service yang berada pada tingkat kematangan dengan indeks 3, maka perlu dilaksanakan peningkatan performansi pada DSS04 dan DSS05 sehingga mampu mencapai level optimal ke depannya.

\section{Kesimpulan}

Pada tahap analisis telah diperoleh proses domain DSS COBIT 5 yang merupakan keseluruhan proses yang sesuai dengan kondisi tata kelola sistem informasi repositori UPT Perpustakaan Universitas Bengkulu yang digunakan sebagai ruang lingkup dan standar audit yaitu DSS01, DSS04 dan DSS05, sehingga domain yang digunakan pada analisis ini hanya domain yang berhubungan dengan IT berupa 
Sistem Informasi Repository. Dari hasil analisis, diketahui ada 2 proses yang mempunyai Level kapabilitas 3 yaitu DSS04 dan DSS05, dan ada 1 proses yang mempunyai Level kapabilitas 4 yaitu DSS01. Level capability keseluruhan yang diperoleh berdasarkan keseluruhan rata-rata adalah 3,1 yang kemudian dapat dibulatkan menjadi 3, yang berarti sebagian besar aktifitas pada domain DSS untuk sistem informasi repositori telah dilakukan namun masih dalam tahap kurang memuaskan, Prosedur telah distandarisasi, didokumentasikan, dan dikomunikasikan melalui pelatihan. Tahap ini mulai mengenal metodologi pengembangan sistem dan masih sangat tergantung individu apakah mengikuti standar yang ada maupun tidak, tetapi telah ada formalisasi untuk setiap kegiatan.

\section{Daftar Pustaka}

[1] National Computing Centre, A Best Practice guide for decision makers in IT THE UK' S LEADING PROVIDER OF EXPERT SERVICES FOR IT PROFESSIONALS. 2005.

[2] H. M. Astuti, F. A. Muqtadiroh, E. W. T. Darmaningrat, and C. U. Putri, "Risks Assessment of Information Technology Processes Based on COBIT 5 Framework: A Case Study of ITS Service Desk," in Procedia Computer Science, 2017, vol. 124, doi: 10.1016/j.procs.2017.12.191.

[3] C. H. Kuntadihardja and A. R. Tanaamah, "Analisis Audit Sistem Informasi Berbasis COBIT 5 Pada Subdomain APO11 Manage Quality,” J. SITECH Sist. Inf. dan Teknol., vol. 2, no. 1, 2019, doi: 10.24176/sitech.v2i1.3492.

[4] ISACA, "Evolution of COBIT 2019 from COBIT 5 | COBIT 2019 updated," 2019 Invensis Learning Pvt Ltd., 2019. .

[5] A. M. Lerner, "Governing the gaps in water governance and land-use planning in a megacity: The example of hydrological risk in Mexico City.," Cities, vol. 83, pp. 61-71, Dec. 2018.

[6] L. N. Amali, M. R. Katili, S. Suhada, and L. Hadjaratie, "The measurement of maturity level of information technology service based on COBIT 5 framework," Telkomnika (Telecommunication Comput. Electron. Control., vol. 18, no. 1, 2020, doi: 10.12928/TELKOMNIKA.V18I1.10582.

[7] A. Asriyanik and M. Hendayun, "Tata Kelola pada Perguruan Tinggi Menggunakan Control Objective for Information \& Related Technology (COBIT) 5," J. Tek. Inform. dan Sist. Inf., vol. 3, no. 1, 2017, doi: 10.28932/jutisi.v3i1.597.

[8] E. W. N. Bernroider and M. Ivanov, "IT project management control and the Control Objectives for IT and related Technology (CobiT) framework," Int. J. Proj. Manag., vol. 29, no. 3, pp. 325-336, 2011, doi: 10.1016/j.ijproman.2010.03.002.

[9] S. Ahriz, A. El Yamami, K. Mansouri, and M. Qbadou, "Cobit 5-based approach for IT project portfolio management: Application to a Moroccan university," Int. J. Adv. Comput. Sci. Appl., vol. 9, no. 4, 2018, doi: 10.14569/IJACSA.2018.090416.

[10] I. G. L. A. Raditya and I. W. D. P. Adnyana, "EVALUASI TATAKELOLA SISTEM INFORMASI AKADEMIK STMIK PRIMAKARA MENGGUNAKAN FRAMEWORK COBIT 5,” J. Teknol. Inf. dan Komput., vol. 5, no. 1, 2019, doi: 10.36002/jutik.v5i1.636.

[11] F. E. N. Saputro, E. Utami, and H. Al Fatta, "Integrasi Framework COBIT 5 dan ITIL V.3 Untuk Membangun Model Tata Kelola Infrastruktur Teknologi Informasi Fachruddin,” Konf. Nas. Sist. Inf., 2018.

[12] J. Lainhart and D. Oliver, "Integrating ISACA frameworks into one overarching framework: COBIT 5," COBIT Focus, vol. 2010, no. 2, 2010.

[13] J. F. Andry, "Audit of IT Governance Based on COBIT 5 Assessments: A Case Study,” J. Nas. Teknol. dan Sist. Inf., vol. 2, no. 2, 2016, doi: 10.25077/teknosi.v2i2.2016.27-34.

[14] R. Febrianingsih and A. Hafiz, "DATA MINING UNTUK MENENTUKAN PRODUK TERLARIS MENGGUNAKAN METODE NAIVE BAYES,” J. Inf. Dan Komput., vol. Vol. 7, no. No.2, 2019.

[15] Naser Khani, Khalil Md Nor, Hossein Hakimpoor, Mojgan Bahrami, and Shahram Salavati, "IS/IT Capability and Strategic Information System Planning (SISP) Success," Int. J. Manag. Inf. Technol., vol. 3, no. 3, pp. 28-37, 2011, doi: 10.5121/ijmit.2011.3303.

[16] A. Gerber, A. Van der Merwe, and R. Alberts, "Practical Implications of Rapid Development Methodologies," in Proceedings of the 2007 Computer Science + Information Technology Education Conference, 2007, pp. 233-245.

[17] S. Fachri Pane, R. M. Awangga, R. Nuraini, and S. Fathonah, “Analysis of Investment IT Planning on Logistic Company Using COBIT 5,” in Journal of Physics: Conference Series, 2018, vol. 1007, no. 1, doi: 10.1088/1742-6596/1007/1/012051.

[18] ISACA, “About COBIT 5 | What is COBIT | Management Framework - ISACA,” Isaca, 2017.

[19] R. Almeida, J. S. Neto, and M. Mira, "Using Analytic Hierarchy Process for COBIT 5 Process Prioritization," Twenty-fourth Am. Conf. Inf. Syst., no. Isaca 2012, 2018.

[20] J. Devos and K. Van De Ginste, "Towards a theoretical foundation of IT governance: the COBIT 5 case,” Electron. J. Inf. Syst. Eval., vol. 18, no. 2, 2015. 
JSAI : Journal Scientific and Applied Informatics

Vol. 4, No. 01, Januari 2021, hal. 20 28

E-ISSN: 2614-3054; P-ISSN: 2614-3062, accredited by Kemenristekdikti, Sinta 5

DOI: 10.36085

[21] S. Kim, Computational Intelligence in Information Assurance and Security, vol. 57. 2007.

[22] Y. Fernando, R. Biilmilah, and D. Darwis, "AUDIT KINERJA SISTEM INFORMASI PENELUSURAN PERKARA PADA PENGADILAN AGAMA TANJUNG KARANG KELAS I A BANDAR LAMPUNG,” J. Tekno Kompak, vol. 11, no. 1, 2017, doi: 10.33365/jtk.v11i1.178.

[23] R. R. Suryono, D. Darwis, and S. I. Gunawan, "Audit Tata Kelola Teknologi Informasi Menggunakan Framework Cobit 5 (Studi Kasus: Balai Besar Perikanan Budidaya Laut Lampung),' J. Teknoinfo, vol. 12, no. 1, 2018, doi: 10.33365/jti.v12i1.38.

[24] S. De Haes, W. Van Grembergen, and R. S. Debreceny, "COBIT 5 and enterprise governance of information technology: Building blocks and research opportunities," J. Inf. Syst., vol. 27, no. 1, 2013, doi: 10.2308/isys-50422.

[25] D. Vernanda, "ANALISIS TINGKAT KEMATANGAN SISTEM INFORMASI PENERIMAAN MAHASISWA BARU," J. Ilm. Ilmu dan Teknol. Rekayasa, vol. 1, no. 1, 2020, doi: 10.31962/jiitr.v1i1.23.

[26] D. H. Murdock and D. H. Murdock, "RACI Chart," in Auditor Essentials, 2018.

[27] C. Feltus, M. Petit, and E. Dubois, "Strengthening employee's responsibility to enhance governance of IT - COBIT RACI chart case study," in Proceedings of the ACM Conference on Computer and Communications Security, 2009, doi: 10.1145/1655168.1655174. 